\title{
Comparison of the Condyle Sagittal Position of Class I and Class II Division 2 in Orthodontic Patients
}

\author{
Murilo Fernando Neuppmann Feres ${ }^{1}$, Osama Eissa², Marina Guimarães Roscoe ${ }^{3}$, Tarek El-Bialy ${ }^{4}$
}

\begin{abstract}
Aim: To compare the condyle sagittal position of class I and class II division 2 in orthodontic patients.

Materials and methods: Fifty orthodontic cases (30 females and 20 males; 12-31 years) from the records of an Orthodontic Graduate Program were collected. Such cases presented cone-beam computed tomography (CBCT) as part of their initial diagnostic examinations. The study sample constituted two groups, i.e. class I and class II division 2 groups. A previously calibrated examiner performed the measurements of the images, representing the distance between the condyle and the articular surface of the glenoid fossa, both anteriorly (anterior disk space-ADS) and posteriorly (posterior disk space-PDS). Descriptive statistics were performed. Data were normally distributed, and parametric tests were used. Paired sample test was used to identify differences between the right and the left joints. Differences between class I and class II/2 groups were tested using independent $t$ test. All statistical tests were interpreted at $5 \%$ significance level.

Results: When the study groups were compared in relation to the dimensions observed for the right and the left ADS and PDS, no significant differences were detected. This study also calculated the differences between right and left disk spaces within the groups, and the differences were not significant for both class I and class II/2 groups.

Conclusion: The results demonstrated, after the performance of a CBCT comparative analysis, that there is no significant difference between class II/2 and class I orthodontic patients in relation to the condyle sagittal position.

Clinical significance: The results collected here refute the expectation of spontaneous mandibular anterior repositioning after correcting the overbite in class II/2 patients.

Keywords: Cone-beam computed tomography, Condylar position, Malocclusion.

The Journal of Contemporary Dental Practice (2020): 10.5005/jp-journals-10024-2867
\end{abstract}

\section{INTRODUCTION}

The class II division 2 (class II/2) malocclusion was originally characterized by Angle as having distal occlusion of the lower teeth, in addition to specific features such as "slight narrowing of the maxillary arch and bunching of the maxillary incisors, with overlapping and lingual inclination."1 Although practitioners intuitively recognize such peculiar occlusal characteristics, there appears to be no full consensus on the exact sagittal skeletal features of this malocclusion. ${ }^{2,3}$ Still, the typical class II/2 vertical skeletal deficiency ${ }^{2,4,5}$ has been documented to establish early and to become more pronounced with age. ${ }^{6}$

Historically, there has been a belief according to which class II/2 patients present their mandible posteriorly entrapped in the glenoid fossa. ${ }^{7,8}$ Such assumption has been reinforced by clinical subjective (yet plausible) observation that retroclined upper incisors might potentially represent relevant oclusal interferences in class II/2 patients with no overjet. ${ }^{9}$ If scientifically ascertained, the elimination of potential interferences could theoretically enable class II correction by spontaneous forward repositioning of the mandible. ${ }^{10,11}$

Therefore, researches are still necessary in order to clarify if class II/2 patients do present posteriorly displaced condyles, especially considering that both class II malocclusions ${ }^{12,13}$ and deep overbites ${ }^{13-16}$ have already been associated with TMJ disorders.

In this sense, several studies have already been investigated condyle sagittal position of class II orthodontic patients. ${ }^{17-24}$ However, part of these articles reported comparative analyzes including class II division 1 and division 2 patients, with no differentiation between these groups. ${ }^{20-23}$ As for the research that

\begin{abstract}
${ }^{1}$ Department of Pediatric Dentistry, University of Sao Paulo, Ribeirao Preto, Sao Paulo, Brazil

${ }^{2}$ Faculty of Dentistry, Tanta University, Egypt

${ }^{3}$ Department of Biomaterials and Oral Biology, University of Sao Paulo, Sao Paulo, Brazil

${ }^{4}$ Department of Dentistry and Dental Hygiene, University of Alberta, Faculty of Medicine and Dentistry, Edmonton, Alberta, Canada

Corresponding Author: Murilo FN Feres, Department of Pediatric Dentistry, University of Sao Paulo, Ribeirao Preto, Sao Paulo, Brazil, Phone: +5511995026484, e-mail: murilo.feres@forp.usp.br

How to cite this article: Feres MFN, Eissa O, Roscoe MG, et al. Comparison of the Condyle Sagittal Position of Class I and Class II Division 2 in Orthodontic Patients. J Contemp Dent Pract 2020;21(9):977-981.

Source of support: Nil

Conflict of interest: None
\end{abstract}

specifically compared class II/2 patients with other malocclusion groups, results concerning the condyle anteroposterior position might be considered controversial if not derived from the application of questionable scientific methods. ${ }^{17-19,24}$

Therefore, the objective of this study was to test the null hypothesis that there is no significant difference in condyle sagittal position among class I and class II/2 orthodontic patients using cone-beam computed tomography (CBCT).

\section{Materials and Methods}

This is a cross-sectional analytical observational study. Sample size was calculated to detect a clinically significant difference of $1.5 \mathrm{~mm}$ 
for the parameter "posterior disk space" (PDS). An a error of 0.05 was set to achieve a test power of $80 \%$. The sample size calculation demonstrated that 25 patients were required in each group.

\section{Patients}

Cone-beam computed tomography scans from 50 orthodontic cases, which had the examination as part of their initial diagnostic examinations, were consecutively collected from the Orthodontic Graduate Program records at the University of of Alberta. Conebeam computed tomography images were acquired for orthodontic purposes, where conventional cephalometric and panoramic radiographs did not provide sufficient information for proper diagnosis and/ or treatment planning, e.g., impacted teeth, airway measurement, and anchorage temporary devices insertion.

\section{Inclusion and Exclusion Criteria}

Data from patients with clinically evident TMJ disorders were not included in the study. In addition, records were excluded if the patient had reported any pain or discomfort in TMJ, as depicted in their clinical records. Neither clicking, crepitation, and limitation of mouth opening, nor mandibular dysfunctions were ever present during the orthodontic treatment admission. Additionally, all patients presented no crossbites, class II subdivisions, asymmetrical facial appearance, nor had positive history of orthodontic treatment, surgery, trauma, or other degenerative joint disease.

\section{Groups}

The study sample constituted two groups. Class I group included records from 25 patients with ANB angle values ranging from $0^{\circ}$ to $4^{\circ 25}$ and bilateral class I molar relationship. Class II division 2 group included records from 25 patients with ANB angle values from $5^{\circ}$ onward. ${ }^{25}$ Furthermore, group II/2 individuals necessarily presented bilateral class II molar relationship, retroclined upper central incisors, and deep overbite (more than 50\%).

Group I included CBCT examinations from 14 female and 11 male patients. These patients had a mean age of 19.0 years $( \pm 6.1)$. Group II was composed of 16 female and 9 male orthodontic patients, with a mean age of 21.6 years $( \pm 7.6)$.

\section{Cone-beam Computed Tomography}

The images were acquired by i-CAT CBCT scan (Imaging Sciences International, Hatfield, PA, USA). The CBCT machine was routinely calibrated, and participants were provided with lead apron. Conebeam computed tomography protocol used in this study was a large field of view $(16 \mathrm{~cm}$ width $\times 13 \mathrm{~cm}$ height), $120 \mathrm{kVp}, 24 \mathrm{mAs}$, 20 seconds, scan time, $0.3 \mathrm{~mm}$ voxel size, and 303 basis projections. Cone-beam computed tomography images were taken with the patients in a sitting upright position with their back as perpendicular to the floor as possible. Their head was stabilized with ear rods inserted in the external auditory meatus.

\section{D Measurements}

The same examiner, who had been previously calibrated, performed the image measurements. Slices $(0.5 \mathrm{~mm})$ from the sagittal sections were evaluated with the anteroposterior diameter of the right and left condyle was the greatest in order to represent the exact distance between the condyle and the articular surface of the glenoid fossa, both anteriorly and posteriorly.

Linear measurements of disk space between condyle and the articular fossa were performed according to lkeda and Kawamura. ${ }^{26}$ From reconstructed sagittal sections, a horizontal line was drawn parallel to Frankfort horizontal plane and tangent to the uppermost area of the glenoid fossa (A). Two other lines originating from (A) were traced tangential to the most anterior (B) and to the most posterior surface $(C)$ of the condyle. A perpendicular distance between $B$ and $D, C$, and $E$ were then measured and considered as anterior disk space (ADS) and PDS distances, respectively (Figs 1 and 2).

Measurements from 16 randomly selected patients, 8 from each group, were repeated after a 2-week interval by the same examiner and compared to calculate the measurement errors.

\section{Data Analyses}

Statistical analysis was performed with SPSS Version 21.0 (SPSS Incorporated, Chicago, IL, USA). Kolmogorov-Smirnov test showed that the data were normally distributed ( $p$ value $>0.05$ ), and thus, parametric tests were used. Descriptive statistics were performed and reported with means and standard deviations for all variables in both groups. A paired sample test was used to identify the significance of differences in disk spaces dimensions of the right and the left joints for the same patient. Differences between the ADS and the PDS in class I and class II/2 groups were tested using independent $t$ test. All statistical tests were interpreted at the $5 \%$ significance level.

\section{Results}

Reliability for CBCT measurements was found to be satisfactory, ${ }^{27}$ as intraclass correlation coefficients ranged from 0.85 to 0.98 . There were no significant differences regarding mean age ( $p$ value $>0.05$ ) or gender distributions ( $p$ value $>0.05$ ).

Mean ADS for Group I was $2.044 \mathrm{~mm}( \pm 0.7066 \mathrm{~mm})$ and 2.048 $\mathrm{mm}( \pm 0.7741 \mathrm{~mm})$ for right and left sides, respectively. Group II presented similar measurements for right $(2.100 \pm 0.7211 \mathrm{~mm})$ and left $(2.188 \pm 1.0191 \mathrm{~mm})$ ADS. When the study groups were compared in relation to the dimensions observed for the right $(p=0.783)$ and left ADS $(p=0.587)$, no significant differences were detected.

As for PDS right and left measurements, group I presented 2.180 $\mathrm{mm}( \pm 0.6096 \mathrm{~mm})$ and $2.260 \mathrm{~mm}( \pm 0.8391 \mathrm{~mm})$, respectively. These values were not significantly different from the ones obtained for group II (right: $p$ value $=0.771$; left: $p$ value $=0.825$ ), which presented

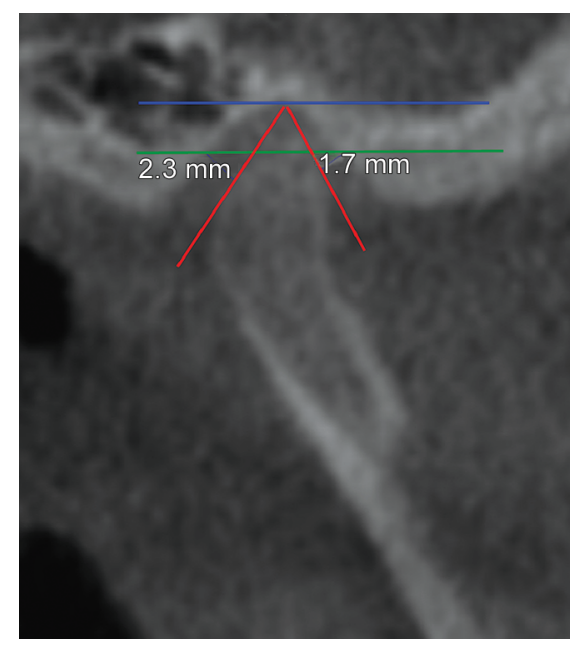

Fig. 1: Measurement of ADS and PDS in a class I individual 
$2.120 \mathrm{~mm}( \pm 0.8211 \mathrm{~mm})$ and $2.208 \mathrm{~mm}( \pm 0.8134 \mathrm{~mm})$ for right and left sides, respectively.

This study also calculated the differences between right and left disk spaces within the groups (Table 1), and the differences were not significant for both class I (ADS: $p$ value $=0.973$; PDS: $p$ value $=0.522$ ) and class II/2 (ADS: $p$ value $=0.625$; PDS: $p$ value $=0.534$ ) groups.

This study has thus verified that there is no significant difference in condyle sagittal position among class I and class II/2 orthodontic patients nor side positional discrepancies, within each one of the groups studied here.

\section{Discussion}

Numerous studies have been performed in order to describe the TMJ as correlated with different malocclusions and skeletal patterns. For instance, studies enrolling class III patients reported wider ${ }^{19,24}$ and shallower fossae, ${ }^{19,28}$ larger articular eminence inclinations, ${ }^{23}$ more anteriorly inclined condylar heads, ${ }^{19}$ and anteriorly displaced condyles. ${ }^{18,24,29,30}$ Hyperdivergent individuals may present more superiorly positioned condyles, ${ }^{31}$ while patients with asymmetric malocclusions, such as in the case of class II or III subdivisions, may as well present asymmetric condylar morphology and/ or positions. $^{32,33}$

It has also been hypothesized by Monje and colaborators ${ }^{34}$ that the counterclockwise rotation of the mandible-as presented in class II/2 patients-may affect both condyle morphology and

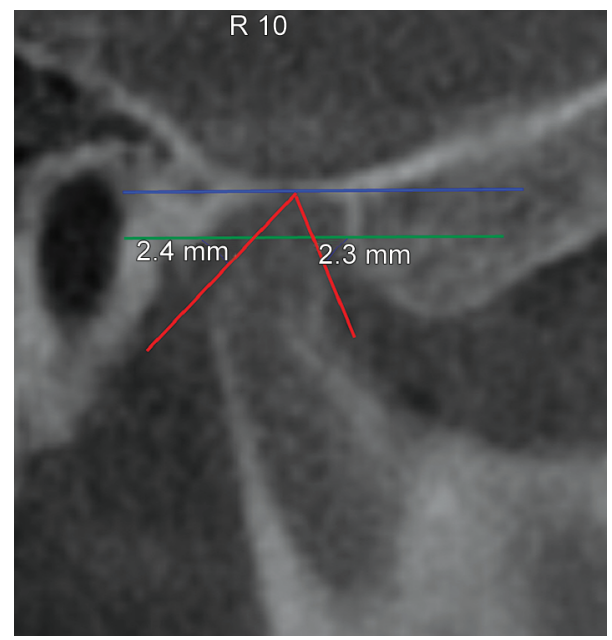

Fig. 2: Measurement of ADS and PDS in a class II/2 individual position. However, the results derived from this study revealed no specific features in relation to the condyle sagittal position of class II/2 orthodontic patients. This finding is in accordance with the study of Pullinger and coworkers ${ }^{17}$ that compared class II/2 with class I individuals. As described by these researches, class II/2 individuals seem to present virtually concentric condyle positions as do class I patients. ${ }^{18}$ This has also been confirmed by our study that revealed similar values for ADS and PDS within both the groups (class I and class II/2) investigated here. Furthermore, this study did not find any positional dissimilarity between right and left sides for neither group. This finding was somehow expected, since the patients enrolled in this study did not present unilateral posterior crossbites or class II subdivisions; and both clinical scenarios are expected to produce asymmetrical condyle positions. ${ }^{32,33,35}$

However, studies with similar comparative groups observed distinct findings when compared to ours. ${ }^{17,24}$ Pullinger and coworkers ${ }^{17}$ presented higher frequencies of posteriorly positioned condyle among class II/2 individuals, although the study sample size was considered to be excessively small for meaningful conclusions. In addition, Song and collaborators, ${ }^{24}$ while evaluating joint spaces in similar groups, found that class II/2, when compared to class I patients, present larger posterior joint spaces and smaller anterior joint spaces. This finding is actually opposed to the original theory, according to which class II/2 patients present posteriorly displaced condyles. ${ }^{7,8}$ Considering our results and the referred literature, ${ }^{17-19,24}$ it is the authors' opinion that the sagittal position of the condyle may not be considered as a reliable predictor for vertical or horizontal facial morphology, as previously observed by Burke and collaborators. ${ }^{36}$

Therefore, the current knowledge seems to also refute the expectation of spontaneous mandibular anterior repositioning after correcting the overbite in class II/2 patients. As depicted in an earlier experimental study performed by Coskuner and $\mathrm{Ciger}^{37}$ even after class II/2 patients had been subjected to maxillary expansion (Quad-helix appliance) and incisors protrusion/ intrusion (utility arches), no significant changes were observed for neither anterior nor posterior joint spaces. In this sense, spontaneous mandibular correction remains unconfirmed as assumed before. ${ }^{38,39}$

Cone-beam computed tomography is currently the most widely used imaging examination method for TMJ and has been extensively indicated as a useful option for evaluating this anatomic area. ${ }^{40}$ However, this study presents limitations, such as the inclusion of patients of a wide age range (12 to 31 years), although both groups presented no significant differences concerning age.

Table 1: Description of the anterior and posterior disk spaces measurements $(\mathrm{mm})$ for right and left sides, and mean differences between groups and sides (within groups)

\begin{tabular}{|c|c|c|c|c|c|c|c|c|}
\hline & & \multicolumn{7}{|c|}{ Group } \\
\hline & & & 1 & & & II/ & & $\Delta$ Groups \\
\hline \multicolumn{2}{|c|}{ Measurement } & Mean & $S D$ & Range & Mean & $S D^{+}$ & Range & Mean/SD \\
\hline \multirow[t]{3}{*}{ ADS } & Right & 2.044 & 0.7066 & $1.2-3.8$ & 2.100 & 0.7211 & $1.0-4.6$ & $\begin{array}{l}-0.056 / \\
(0.202)\end{array}$ \\
\hline & Left & 2.048 & 0.7741 & $1.2-4.4$ & 2.188 & 1.0191 & $0.8-5.6$ & $\begin{array}{l}-0.140 / \\
(0.256)\end{array}$ \\
\hline & $\Delta \mathrm{RL}$ & -0.004 & 0.581 & - & -0.088 & 0.890 & - & - \\
\hline \multirow[t]{3}{*}{ PDS } & Right & 2.180 & 0.6096 & $1.3-3.7$ & 2.120 & 0.8211 & $0.8-4.2$ & $0.060 /(0.205)$ \\
\hline & Left & 2.260 & 0.8391 & $0.7-3.8$ & 2.208 & 0.8134 & $1.1-4.4$ & $0.052 /(0.234)$ \\
\hline & $\Delta \mathrm{RL}$ & -0.080 & 0.616 & - & -0.088 & 0.698 & - & - \\
\hline
\end{tabular}

$\mathrm{SD}^{\dagger}$ : standard-deviation; $\Delta \mathrm{Groups}$ : difference between groups (mean/SD); $\triangle \mathrm{RL}$ : difference between sides (mean/SD) 
There were no comparative analyzes including class II division 1 or class III individuals. Instead, this study preferred to focus on providing information regarding the hypothetical malposition of class II/2 patients' condyle. Also, records were collected from a single center, which might not truly mimic what is expected to represent the class II/2 population.

Still, it is necessary to emphasize that the sample was consecutively recruited, which might diminish potential selection biases. Although sample size was considered to be adequate, future studies should include a broader range of malocclusions and evaluation measurements.

\section{ConcLusion}

The results from this study demonstrated, after the performance of a CBCT comparative analysis, that there is no significant difference between class II/2 and class I orthodontic patients in relation to the condyle sagittal position.

\section{Clinical Significance}

The results collected here refute the expectation of spontaneous mandibular anterior repositioning after correcting the overbite in class II/2 patients.

\section{ACKNOWLedgments}

This study was approved by the Human Research Ethics Board at the University of Alberta, Edmonton, Alberta. Canada (Protocol \# 000000000000).

\section{References}

1. Angle EH.Classification of malocclusion. Dent Cosmos 1899;41(3):248264.

2. Isik F, Nalbantgil D, Sayinsu K, et al. A comparative study of cephalometric and arch width characteristics of class II division 1 and division 2 malocclusions. Eur J Orthod 2006;28(2):179-183. DOI: 10.1093/ejo/cji096.

3. Al-Khateeb EA, Al-Khateeb SN. Anteroposterior and vertical components of class II division 1 and division 2 malocclusion. Angle Orthod 2009;79(5):859-866. DOI: 10.2319/062208-325.1.

4. Prasad SE, Indukuri RR, Singh R, et al. Pathognomonic features of angle's class II division 2 malocclusion: a comparative cephalometric and arch width study. J Int Soc Prev Community Dent 2014;4(Suppl 2):S105-S109. DOI: 10.4103/2231-0762.146212.

5. Uzuner FD, Aslan BI, Dinçer M. Dentoskeletal morphology in adults with class I, class II division 1, or class II division 2 malocclusion with increased overbite. Am J Orthod Dentofacial Orthop 2019;156(2): 248-256.e2. DOI: 10.1016/j.ajodo.2019.03.006.

6. Barbosa LAG, Araujo E, Behrents RG, et al. Longitudinal cephalometric growth of untreated subjects with class II division 2 malocclusion. Am J Orthod Dentofacial Orthop 2017;151(5):914-920. DOI: 10.1016/ j.ajodo.2016.10.026.

7. Stack BC, Funt LA. Temporomandibular joint dysfunction in children. J Pedod 1977;1(3):240-247.

8. Thompson JR. Abnormal function of the temporomandibular joints and related musculature. Orthodontic implications. part II. Angle Orthod 1986;56(3):181-195. DOI: 10.1043/0003-3219(1986)0562.0.CO;2.

9. Gianelly AA, Petras JC, Boffa J. Condylar position and class II deepbite, no-overjet malocclusions. Am J Orthod Dentofacial Orthop 1989;96(5):428-432. DOI: 10.1016/0889-5406(89)90328-4.

10. Gianelly AA. Rapid palatal expansion in the absence of crossbites: added value? Am J Orthod Dentofacial Orthop 2003;124(4):362-365. DOI: 10.1016/S0889-5406(03)00568-7.
11. Lima Filho RM, Lima AC, de Oliveira Ruellas AC. Spontaneous correction of class II malocclusion after rapid palatal expansion. Angle Orthod 2003;73(6):745-752. DOI: 10.1043/0003-3219(2003)0732.0.CO;2.

12. Mohlin BO, Derweduwen K, Pilley R, et al. Malocclusion and temporomandibular disorder: a comparison of adolescents with moderate to severe dysfunction with those without signs and symptoms of temporomandibular disorder and their further development to 30 years of age. Angle Orthod 2004;74(3):319-327. DOI: 10.1043/0003-3219(2004)0742.0.CO;2.

13. Costa MD, Froes Junior GRT, Santos CN. Evaluation of occlusal factors in patients with temporomandibular joint disorder. Dental Press J Orthod 2012;17(6):61-68. DOI: 10.1590/S2176-94512012000600015.

14. Almăşan OC, Băciuţ $M$, Almăşan $H A$, et al. Skeletal pattern in subjects with temporomandibular joint disorders. Arch Med Sci 2013;9(1):118126. DOI: 10.5114/aoms.2013.33072.

15. Bilgiç F, Gelgör IE. Prevalence of temporomandibular dysfunction and its association with malocclusion in children: an Epidemiologic study. J Clin Pediatr Dent 2017;41(2):161-165. DOI: 10.17796/10534628-41.2.161.

16. Mollabashi V, Heidari A, Ebrahimizadeh H, et al. The study of facial morphology in patient with vertical growth pattern (hyperdivergent) lacking or showing TMD symptoms. J Stomatol Oral Maxillofac Surg 2019;:S2468-7855(19):30224-1.

17. Pullinger AG, Solberg WK, Hollender $L$, et al. Relationship of mandibular condylar position to dental occlusion factors in an asymptomatic population. Am J Orthod Dentofacial Orthop 1987;91(3):200-206. DOI: 10.1016/0889-5406(87)90447-1.

18. Cohlmia JT, Ghosh J, Sinha PK, et al. Tomographic assessment of temporomandibular joints in patients with malocclusion. Angle Orthod 1996;66(1):27-35. DOI: 10.1043/0003-3219(1996)0662.3.CO;2.

19. Fernández Sanromán J, Gómez González JM, del Hoyo JA. Relationship between condylar position, dentofacial deformity and temporomandibular joint dysfunction: an MRI and CT prospective study. J Craniomaxillofac Surg 1998;26(1):35-42. DOI: 10.1016/s10105182(98)80033-4.

20. Katsavrias EG, Halazonetis DJ. Condyle and fossa shape in class II and class III skeletal patterns: a morphometric tomographic study. Am J Orthod Dentofacial Orthop 2005;128(3):337-346. DOI: 10.1016/j. ajodo.2004.05.024.

21. Paknahad M, Shahidi S, Abbaszade H. Correlation between condylar position and different sagittal skeletal facial types. J Orofac Orthop 2016;77(5):350-356. DOI: 10.1007/s00056-016-0039-z.

22. Akbulut $A, K ı$ Iınç DD. Evaluation of condyle position in patients with angle class I, II, and III malocclusion using cone-beam computed tomography panoramic reconstructions. Oral Radiol 2019;35(1): 43-50. DOI: 10.1007/s11282-018-0326-z.

23. Lobo F, Tolentino ES, Iwaki LCV, et al. Imaginology tridimensional study of temporomandibular joint osseous components according to sagittal skeletal relationship, sex, and age. J Craniofac Surg 2019;30(5):1462-1465. DOI: 10.1097/SCS.0000000000005467.

24. Song J, Cheng M, Qian Y, et al. Cone-beam CT evaluation of temporomandibular joint in permanent dentition according to angle's classification. Oral Radiol 2020;36(3):261-266. DOI: 10.1007/ s11282-019-00403-3.

25. Steiner CC. Cephalometrics for you and me. Am J Orthod 1953;39(10):729-755. DOI: 10.1016/0002-9416(53)90082-7.

26. Ikeda K, Kawamura A. Assessment of optimal condylar position with limited cone-beam computed tomography. Am J Orthod Dentofacial Orthop 2009;135(4):495-501. DOI: 10.1016/j.ajodo.2007.05.021.

27. Koo TK, Li MY. A guideline of selecting and reporting intraclass correlation coefficients for reliability research. J Chiropr Med 2016;15(2):155-163. DOI: 10.1016/j.jcm.2016.02.012.

28. Arieta-Miranda JM, Silva-Valencia M, Flores-Mir C, et al. Spatial analysis of condyle position according to sagittal skeletal relationship, assessed by cone beam computed tomography. Prog Orthod 2013;14(1):36. DOI: 10.1186/2196-1042-14-36.

29. Rodrigues AF, Fraga MR, Vitral RW. Computed tomography evaluation of the temporomandibular joint in class I malocclusion 
patients: condylar symmetry and condyle-fossa relationship. Am J Orthod Dentofacial Orthop 2009;136(2):192-198. DOI: 10.1016/ j.ajodo.2007.07.032.

30. Kaur A, Natt AS, Mehra SK, et al. Improved visualization and assessment of condylar position in the glenoid fossa for different occlusions: a CBCT study. J Contemp Dent Pract 2016;17(8):679-686. DOI: 10.5005/jp-journals-10024-1912.

31. Park IY, Kim JH, Park YH. Three-dimensional cone-beam computed tomography based comparison of condylar position and morphology according to the vertical skeletal pattern. Korean J Orthod 2015;45(2):66-73. DOI: 10.4041/kjod.2015.45.2.66.

32. de Mattos JM, Palomo JM, de Oliveira Ruellas AC, et al. Threedimensional positional assessment of glenoid fossae and mandibular condyles in patients with class II subdivision malocclusion. Angle Orthod 2017;87(6):847-854. DOI: 10.2319/121216-890.1.

33. Huang $\mathrm{M}, \mathrm{Hu} \mathrm{Y}, \mathrm{Yu}$ J, et al. Cone-beam computed tomographic evaluation of the temporomandibular joint and dental characteristics of patients with class II subdivision malocclusion and asymmetry. Korean J Orthod 2017;47(5):277-288. DOI: 10.4041/kjod.2017.47.5.277.

34. Monje F, Delgado E, Navarro MJ, et al. Changes in the temporomandibular joint caused by the vertical facial pattern. Study Experim Model J Craniomaxillofac Surg 1994;22(6):361-370. DOI: 10.1016/s1010-5182(05)80118-0.
35. Velásquez RL, Coro JC, Londoño A, et al. Three-dimensional morphological characterization of malocclusions with mandibular lateral displacement using cone-beam computed tomography. Cranio 2018;36(3):143-155. DOI: 10.1080/08869634.2017. 1300994.

36. Burke G, Major P, Glover K, et al. Correlations between condylar characteristics and facial morphology in class II preadolescent patients. Am J Orthod Dentofacial Orthop 1998;114(3):328-336. DOI: 10.1016/s0889-5406(98)70216-1.

37. Coskuner HG, Ciger S. Three-dimensional assessment of the temporomandibular joint and mandibular dimensions after early correction of the maxillary arch form in patients with class II division 1 or division 2 malocclusion. Korean J Orthod 2015;45(3):121-129. DOI: 10.4041/kjod.2015.45.3.121.

38. Volk T, Sadowsky C, Begole EA, et al. Rapid palatal expansion for spontaneous class II correction. Am J Orthod Dentofacial Orthop 2010;137(3):310-315. DOI: 10.1016/j.ajodo.2008.05.017.

39. Feres MF, Raza H, Alhadlaq A, et al. Rapid maxillary expansion effects in class II malocclusion: a systematic review. Angle Orthod 2015;85(6):1070-1079. DOI: 10.2319/102514-768.1.

40. Caruso S, Storti E, Nota A, et al. Temporomandibular joint anatomy assessed by CBCT images. Biomed Res Int 2017;2017:2916953. DOI: $10.1155 / 2017 / 2916953$. 